\title{
Consciência e inevidência do eu em Malebranche
}

\author{
Adelino Cardoso
}

\begin{abstract}
"Mas a maior parte dos homens não reflectem bastante sobre a diferença que existe entre conhecer e sentir; entre um conhecimento claro e evidente, e o sentimento interior. Imaginam que conhecem claramente o que sentem vivamente; e que não conhecem, e são mesmo incapazes de conhecer as verdades claras e evidentes que os tocam pouco, e às quais por conseguinte dão pouca atenção. E é isso que os lança numa infinidade de preconceitos"'.
\end{abstract}

1. Tal como hoje, a noção de consciência revela-se problemática - no que respeita ao seu âmbito, estatuto e significação - aquando da sua inscrição no cerne da filosofia por efeito de pensadores eminentes do século XVII, entre os quais Descartes e Locke 2.

O modo de entrada đa consciência no léxico filosófico moderno é, desde logo, significativo. Descartes atribui- Ihe um lugar central no seu sistema, afirmando a solidariedade estreita e a coextensividade entre pensamento e consciência ${ }^{3}$. Não obstante, o termo consciência é muito raro na produção filosófica cartesiana e a tematização que o autor faz dela é incipiente: faltou-lhe assumir decisões capazes de imprimir uma orientação relativamente definida à questão. Descartes chegou ao ponto de encruzilhada, vislumbrou os problemas, mas não os defrontou na busca de caminhos. Não admira, por conseguinte, que a sua posteridade imediata se tenha envolvido em animado debate, seguindo orientações ostensivamente contrárias e inconciliáveis. O ortodoxo Arnauld e o heterodoxo Malebranche sinalizam caminhos divergentes: o de uma consciência intencional e representativa em face de uma consciência afectada e receptiva.

Na definição de pensamento que é dada no texto latino dos Principios da Filosofia, o pensamento é o fenómeno consciente enquanto tal: "Pelo termo pensamento entendo todas aquelas coisas que ocorrem em nós quando estamos conscientes, na medida em

I Malebranche, Réflexions sur la Prémotion physique, (Oeuvres Complètes), tomo XVI, Paris, Vrin, pp. 30-31. As citações de Malebranche serão feitas a partir da edição das Obras completas, publicada pelas ed. Vrin, sob a direcção de A. Robinet. Indicar-se-á o título da obra citada, volume e página da edição referida.

2 A este respeito, discordo da posição de Natalie Depraz segundo a qual há uma significação fundamental da consciência, que liga as diferentes perspectivas dos pensadores do século XVII: "Cada um traça um perfil incessantemente único do rosto da consciência: esta encontra a sua unidade complexa na pluralidade destas perspectivas singulares". (Depraz, N., La conscience. Approches croisées, des classiques aux sciences cognitives, Paris, A. Colin, 2001, p. 17).

3 Nas Respostas às terceiras Objecções, pensamento, percepção e consciência são tomados como sinónimos: "E, depois, há os actos a que chamamos cogitativos, como entender, querer, imaginar, sentir, etc, que convêm todos sob a razão comum de pensamento, ou percepção ou consciência (cogitationis, sive perceptionis, sive conscientiae)". (AT, VII, p. 176). 
que há em nós consciência delas"4. A tradução francesa, revista pelo autor ${ }^{5}$, mostra que o termo consciência recobre o âmbito da percepção imediata das ocorrências internas do eu. Assim, a consciência qualifica o exercício do pensar enquanto acontecimento meu, que experiencio imediatamente em mim: “.... e não pode haver em nós nenhum pensamento do qual não estejamos conscientes (conscii) naquele preciso momento em que está em nós" ${ }^{\prime \prime}$. Por via dela, realiza-se a pertença das operações intelectuais ao eu pensante. Ela é um traço unificador da vida mental, desempenha uma função de unidade. O eu dá-se na consciência de si, a sua figura própria é a de um sujeito de acção.

No léxico das Meditações, a percepção tipifica o estilo de relação consigo? O cogito é assimilado a uma percepção: a percepção de um eu singular que faz a experiência do seu próprio pensar. Percepção e a forma verbal perceber são os termos que organizam o çampo do pensar no seu modo peculiar de exercício, isto é, enquanto consciência. É pela percepção que se dá o acesso ao pensar: é ela que exprime a especificidade da consciência. O que levanta uma constelação de problemas. A percepção de si é intelecção de uma ideia ou uma simples experiência? Trata-se de uma intuição no sentido fenomenológico do termo ou de um exercício reflexivo pelo qual o eu se desdobra em sujeito e objecto de si mesmo? É um acto instantâneo e descontínuo ou uma instância que garante a permanência e continuidade de uma mesma substância pensante? A substancialização do eu é extensiva à consciência ou esta situa-se num plano distinto do metafísico-entitativo? Descartes mantém, a este respeito, uma assinalável margem de ambiguidade, fornecendo indicações díspares, seja numa direcção fenomenológica ${ }^{8}$ ou estritamente metafísica?

2. Malebranche inaugura a filosofia da consciência ao assumi-la como auto- afecção originária do eu pensante, um sentimento de si desprovido de correlato objectal, uma experiência que resiste ao esforço de conceptualização. A consciência, identificada com o sentimento interior, é a única via de acesso ao pensamento: “... só por sentimento interior ou por consciência é que conhecemos o pensamento" 10 .

A primeira tematização da consciência, no capítulo VII do III livro da RV, vem na sequência do questionamento da pretensão de erigir o sujeito pensante no papel de fundamento do saber. É esse o significado da teoria da visão em Deus e correlativa rejeição do inatismo cartesiano e da tese segundo a qual o sujeito é fonte de inteligibilidade. O cogito não é o paradigma do saber, a sua verdade é a de um facto, uma experiência incontestável ${ }^{11}$, não uma proposição universal. Malebranche opõe-

4 "Cogitationis nomine, intelligo illa omnia, quae nobis consciis in nobis fiunt, quatenùs eorum in nobis conscientia est". (Principa, art. IX, AT, VIII-I, p. 7).

5 "Pela palavra pensar entendo tudo o que ocorre em nós de tal maneira que o apercebemos imediatamente por nós próprios". ("Par le mot de penser, j'entends tout ce qui se fait en nous de telle sorte que nous l'apercevons immédiatement») (AT, IX-2, p. 28).

6 Quartas Respostas às Objecções, AT VII, p. 246.

7 Acerca deste tópico, remeto o leitor para a obra em fase de acabamento $O$ Trabalho da mediação no pensamento leibniziano.

$8 \mathrm{M}$. Henry assume vigorosamente a cogitatio cartesiana como momento inaugural da fenomenologia. Veja-se em particular Henry, Michel, «Le commencement cartésien et l'idée de la phénoménologie», in Depré, O. e Lories, D., Lire Descartes aujourd'hui, Louvain-Paris, Ed. Peeters, 1997, pp. 199-212.

9 Carlos Silva, enfatiza a tendência metafísica do cartesianismo, ao afirmar que «a "descoberta" cartesiana não é a da subjectividade, mas a da substantividade do ego" (Silva, Carlos, "A vontade de pensar ou a cogitatio segundo o voluntarismo cartesiano", in Santos, L. R., Alves, Pedro e Cardoso, Adelino, Descartes, Leibniz e a Modernidade, Lisboa, Ed. Colibri, 1998, p. 66).

10 Recherche de la vérité, (Oeuvres Complètes, tomo I, p. 382).

11 "Por experiências incontestáveis entendo principalmente os factos que a fé nos ensina e aqueles dos quais somos convencidos pelo sentimento interior que temos daquilo que se passa em nós". (Traité de Morale, I, V, XVI, (Oeuvres Complètes, tomo XI, p. 66). 
-se, assim, ao intento cartesiano de uma mathesis universalis, expressa na homogeneidade de procedimentos. Na formulação do autor, há quatro "maneiras de ver as coisas", que correspondem a modos de inteligibilidade distintos: o conhecimento por simples visão, que opera por intuição intelectual; o conhecimento representacional, que foca os objectos a partir da ideia geral que os inteligibiliza; o conhecimento por consciência ou sentimento interior de si; o conhecimento por conjectura, transpondo para o outro a experiência que se tem de si mesmo ${ }^{12}$.

Em sentido preciso, só a intuição e intelecção ideativa são propriamente conhecimentos. A consciência fica aquém dos requisitos de um verdadeiro saber: o conhecimento que ela fornece, é inapelavelmente imperfeito. O Filósofo Oratoriano opera uma inversão da ordem cartesiana das razões e fá-lo de um modo ostensivo nos Esclarecimentos (Eclaircissements) X e XI. Mantendo e reforçando o dualismo cartesiano, o autor afirma a plena inteligibilidade do corpo, ao mesmo tempo que nega liminarmente a possibilidade de a alma conhecer a sua própria essência.

No Esclarecimento X, é introduzida a noção de extensão inteligível, na qual se funda a ciência geométrica dos corpos. A relevância da extensão inteligível será progressivamente maior nas obras subsequentes: nas Meditações Cristãs e Metafisicas, é apresentada como a própria "imensidão divina enquanto participável pelas criaturas"13; nas Conversas sobre Metafisica, assume o estatuto de arquétipo ${ }^{14}$ que fornece a proto-inteligibilidade dos corpos. Na filosofia malebranchiana da luz, os corpos pertencem à zona obscura, não sendo visíveis por si mesmos, no entanto essa incapacidade de se fazerem ver é compensada pelo brilho da extensão pura e inteligível, que é o foco luminoso da razão natural. Em síntese, a extensão inteligível unifica a física na acepção geral de ciência das coisas materiais.

O Esclarecimento XI complementa o anterior. Num tom acerbamente anti-cartesiano, afirma-se peremptoriamente a asssimetria entre a ideia clara da extensão, da qual podemos deduzir todas as propriedades geométricas do corpo, e a opacidade inerente à ideia que temos da alma. O léxico utilizado para a extensão é o da evidência e da intuição: apreendêmo-la por simples visão (de simple vue) $)^{15}$, "sem raciocínio" (sans

12 "A primeira [maneira de ver as coisas] é conhecer as coisas por si mesmas.

A segunda, conhecê-las pelas suas ideias, isto é, tal como o entendo aqui, por alguma coisa que seja diferente delas.

A terceira, conhecê-las por consciência ou por sentimento interior.

A quarta, conhecê-las por conjectura.

Conhecem-se as coisas por si mesmas e sem ideias, quando elas são inteligíveis por si mesmas, isto é, quando podem agir sobre o espírito e, mediante isso, revelar-se-lhe. (...) Conhecem-se as coisas pelas suas ideias quando elas não são inteligíveis por si mesmas, seja porque elas são corporais, seja porque não podem afectar o espírito e revelar-se-lhe. Conhecem-se por consciência todas as coisas que não são distintas de si. Finalmente, conhecem-se por conjectura as coisas que são diferentes de si e daquelas que se conhecem em si mesmas e por ideias, como quando se pensa que certas coisas são semelhantes a algumas outras que se conhece". (Recherche de la vérité, Oeuvres Complètes, tomo I, pp. 448-449).

13 "Mas deves distinguir duas espécies de extensão, uma inteligível e outra material. A extensão inteligível é eterna, imensa, necessária. É a imensidão do ser divino enquanto infinitamente participável pela criatura corporal, enquanto representativo de uma matéria imensa, numa palavra, a ideia inteligível de uma infinidade de mundos possíveis. É por essa extensão inteligível que tu conheces este mundo visível porquanto o mundo que Deus criou é invisível por si mesmo. A matéria não pode agir sobre o teu espírito nem representar-se-lhe". (Meditations Chrétiennes et Métaphysiques, (Oeuvres Complètes, tomo X, p. 99).

14 "Teodoro - Meu caro Aristo, consulta atentamente as ideias claras. São elas que difundem nos espíritos atentos a luz que te falta. Contempla o arquétipo dos corpos, a extensão inteligível. É ela que os representa, já que foi sobre ela que todos eles foram formados. Essa ideia é luminosa. Consulta-a, pois". (Entretiens sur la métaphysique et sur la religion, (Oeuvres Complètes, tomos XII-XIII, pp. 154-155).

15 A locução de simple vue repete-se por diversas vezes nas pp. 164-166 (Oeuvres complètes, tomo III). 
raisonnement ${ }^{16}$. Por seu lado, a alma carece inteiramente de evidência, a ideia que temos dela é irremediavelmente confusa: "Como é que, por conseguinte, eles [os cartesianos] podem defender que se conhece mais claramente a natureza da alma do que a do corpo, já que a ideia do corpo ou da extensão é tão clara que toda a gente está de acordo acerca do que ela contém e do que ela exclui, e que a da alma é tão confusa que os próprios cartesianos disputam todos os dias se as modificações de cor lhe pertencem ou não?"17.

Daí a pergunta, ostensivamente provocatória, dirigida aos cartesianos: "Onde está, então, a ideia clara da alma, a fim de que os cartesianos a consultem?"18. O próprio Malebranche responde à pergunta, excluindo a possibilidade de a alma se intuir imediatamente a si mesma: “... eles não a verão nunca por simples visão ( $d$ 'une simple vûe), não a descobrirão nunca consultando a pretensa ideia da alma" (ibid.).

Algo surpreendentemente, o corpo é objecto de apreensão inteligível, ao passo que a alma espiritual só sensivelmente se apreende a si mesma. E reside aí a originalidade da consciência: ela é puro sentimento de si, cuja verdade não carece de legitimação extrínseca. A alegria é estar alegre e o modo como isso me advém. O sentimento e o modo dele são uma e a mesma coisa. A dualidade ser/aparência não joga aqui: a realidade do sentimento consiste inteiramente na vivência que faço dele, sem resto. A sua imperfeição no plano intelectual não significa que ele seja falso, mas apenas que o seu modo de manifestação e veridição não obedece aos cânones da racionalidade típica da ciência matemática, que serye de paradigma a Malebranche e à corrente mais representativa do seu tempo: "É verdade que o conhecimento que temos da nossa alma através da consciência é imperfeito, mas não é falso", a consciência "não nos induz em erro"'19. Mais explicitamente, "embora os sentidos te enganem sempre, a tua consciência ou o sentimento interior do que se passa em ti não engana nunca" 20 . O erro deriva da nossa tendência a atribuir valor representativo aos nossos estados de consciência, que Malebranche designa como "percepções" ou "modalidades da nossa alma".

Em Recherche de la Vérité, Malebranche delimita o âmbito e significado da consciência: "É certo que a alma vê em si mesma e sem ideias todas as sensações e todas as paixões que a impressionam actualmente, o prazer, a dor, o frio, o calor, as cores, os sons, os odores, os sabores, o seu amor, o seu ódio, a sua alegria, a sua tristeza, e as outras; porque todas as sensações e todas as paixões da alma não representam nada que exista fora dela, que se lhes assemelhe, e porque elas são meras modificações de que o espírito é capaz"21. A consciência abarca todos os fenómenos internos do nosso eu - sentimentos, desejos, paixões, volições - na medida em que os apercebemos imediatamente. Sem margem de ambiguidade, afirma-se que os estados internos do eu pensante não representam nada de exterior, exprimindo apenas o modo como somos afectados. No livro IV da mesma obra, o autor vai mais longe: os nossos estados internos não representam nada de exterior nem de interior, não sendo sequer representativos de si mesmos. Nos termos do Filósofo oratoriano: "Mas é tão falso que as modalidades da alma sejam representativas de todos os seres que elas não podem sê-lo de nenhum, nem mesmo do que elas são. Porque, embora nós tenhamos sentimento interior da nossa existência e das nossas modalidades actuais, de modo nenhum as conhecemos"22 . Percepção e representação não jogam uma com a outra: "Percepções representativas são duas palavras que não combinam bem entre si"'23.

16 Op. cit., p. 165.

17 Op. cit., p. 167

18 Op. cit., p. 166.

19 Recherche de la vérité, (Oeuvres Complètes, tomo I, p. 453).

20 Meditations Chrétiennes et Métaphysiques, VI, 7, (Oeuvres Complètes, tomo X, p. 61).

21 Recherche de la vérité, (Oeuvres Complètes, tomo I, p. 433).

22 Recherche de la vérité, (Oeuvres Complètes, tomo II, p. 97).

23 Recueil de toutes les réponses à Monsieur Arnauld, (Oeuvres Complètes, tomos VIII-IX, p. 920). 
Sentimento e luz excluem-se mutuamente ${ }^{24}$. O sentimento de si é intrinsecamente opaco, passa inteiramente ao lado daquilo que eu sou: "O sentimento interior que tenho de mim mesmo ensina-me que eu sou, que penso, que quero, que sinto, que sofro, etc., mas de modo nenhum me dá a conhecer o que eu sou, a natureza do meu pensamento, da minha vontade, dos meus sentimentos, das minhas paixões, da minha dor, nem as relações que todas estas coisas têm umas com as outras"25. A vivacidade do sentimento não diminui a sua obscuridade, aumenta-a: "Quanto mais os nosso sentimentos são vivos, mais eles difundem trevas"26.

A consciência é uma estrutura basicamente afectiva ${ }^{27}$ : ao olharmos para dentro de nós "vemos apenas os nossos sentimentos, e não as coisas que desejamos ver e que cremos falsamente que vemos" ${ }^{\prime 2}$. A capacidade representativa da consciência é uma - ilusão que deturpa o significado da consciência ao identificá-la com a intencionalidade e radica na pretensão do eu pensante a ser autor e fundamento das ideias mediante as quais representa os objectos. Pretensão absolutamente infundada, que é refutada pelo tipo de experiência que temos de nós próprios, já que o sentimento de si mostra que o eu se não faz a si mesmo, que a passividade pertence ao seu estrato mais originário: "É verdade que eu me sinto, mas não me vejo, não me conheço. E se me sinto é porque me tocam, já que eu não posso agir em mim" "29.

Os termos em que o autor pergunta pelo estatuto das ideias na sua relação com o sujeito cognoscente são elucidativos: "Mas a dificuldade consiste em saber se as ideias que representam alguma coisa que existe fora da alma e que de alguma maneira se lhes assemelha, como as ideias do Sol, de uma casa, um cavalo, um ribeiro, etc. são meras modificações da alma: de maneira que o espírito apenas precise de si mesmo para se representar todas as coisas que existem fora dele" ${ }^{\text {30 }}$. Pelo modo de posição da questão, ao problematizar o vínculo entre operação do sujeito e inteligibilidade, este texto é o momento inicial do debate em torno do psicologismo. Percepção e ideia são uma e a mesma coisa vista sob dois ângulos diferentes ou são planos irredutivelmente díspares?

A distinção entre percepção e ideia ${ }^{31}$ é um dos tópicos nucleares da filosofia malebranchiana: a ideia é uma entidade inteligível, independente do facto de ser ou não percebida, não é o resultado da operação intelectiva pela qual a apreendemos ${ }^{32}$. A concepção do espírito é incapaz de fundar a realidade da ideia em virtude do seu

24 "Parece-me muito útil considerar que o espírito apenas conhece os objectos de duas maneiras: por luz e por sentimento. Vê as coisas por luz, quando tem uma ideia clara a seu respeito e pode, consultando essa ideia, descobrir todas as propriedades de que elas são susceptíveis. Vê as coisas por sentimento, quando não encontra em si próprio uma ideia clara das coisas para a consultar e não pode, assim, descobrir claramente as suas propriedades, conhecendo-as apenas por um sentimento confuso, sem luz e sem evidência". (Eclaircissement X, (Oeuvres Complètes, tomo III, pp. 141-142).

25 Malebranche, Entretiens sur la métaphysique et sur la religion, Oeuvres Complètes, tomos XII-XIII, p. 67.

26 Ibid., p. 68.

27 Mafalda Blanc realçou bem este aspecto: "Mais do que simplesmente passivo ou sem intencionalidade, o que melhor caracteriza o espírito é a sua estrutura receptiva de carácter afectivo, quer dizer, uma capacidade muito geral de se deixar impressionar e modificar por toda a espécie de sentimentos e sensações, uma faculdade de tudo experimentar através do gozo e do sofrimento". (Blanc, Mafalda Faria, O amor de Deus na filosofia de Malebranche, Lisboa, IN-CM, 1998, pp. 296-297).

28 Recherche de la vérité, (Oeuvres Complètes), tomo II, p. 88.

29 Méditations Chrétiennes et Métaphysiques, II, 4, Oeuvres Complètes, tomo X, p. 19.

30 Ibidem.

31 Esta distinção recobre a assimetria entre conhecer e sentir: "Tu sentes as tuas modificações, mas não as conheces; conheces as tuas ideias e as coisas mediante as suas ideias, mas não as sentes" (Recueil de toutes les réponses à Monsieur Arnauld, Oeuvres Complètes, tomos VI-VII, p. 72).

32 A tese de que as ideias são "seres reais porque têm propriedades reais" (Recherche de la vérité, III, II, 3, Oeuvres Complètes, tomo II, p. 423), sucessivamente retomada, é enfatizada 
carácter de generalidade e universalidade, ao passo que o acto pensante é necessariamente particular: "Como é que tu, que és um ser particular, te modificarias para te representares uma figura em geral?"33. Uma mesma ideia pode ocasionar uma multiplicidade de percepções diferentes ${ }^{34}$. Por muito luminosa que seja uma ideia, v. g. a extensão inteligível, ela será sempre outra coisa, algo distinto da minha percepção dela: "A percepção que eu tenho da extensão inteligível pertence-me: é uma modificação do meu espíritc. Sou eu que apercebo essa extensão. Mas a extensão que eu apercebo não é uma modificação do meu espírito. (...) A percepção que eu tenho da extensão não pode existir sem mim. Logo, é uma modificação do meu espírito. Mas a extensão que eu vejo subsiste sem mim"35.

O grau máximo de ajustamento entre ideia e percepção ocorre quando esta assume plenamente o seu carácter receptivo, apagando a marca subjectiva do pensar. É esse o trabalho próprio da atenção: dispor o espírito a receber o fulgor da evidência, cujo excesso de luminosidade se impõe ao sujeito. Antecipando uma linha fundamental da fenomenologia de M. Henry ${ }^{36}$, Malebranche assinala a radical heterogeneidade entre cogitatio e evidência ${ }^{37}$. Com efeito, eu posso conhecer distintamente as propriedades do círculo e as relações entre as suas partes, mas não o acto pelo qual concebo as suas propriedades: "Todas as nossas percepções em geral nos são desconhecidas: as nossas sensações, a cor, o calor, o sabor, o odor, etc. as percepções puras tal como as percepções sensíveis. A percepção que temos de um círculo, por exemplo, não a conhecemos mais claramente do que a sensação ou o gosto de um fruto. Compreendemos claramente o que é um círculo, mas de modo nenhum compreendemos a percepção que temos dele, e isso pela simples razão de que temos a ideia clara da extensão, e por seu intermédio de um círculo, e de que não temos ideia clara da nossa alma nem, consequentemente, da nossa percepção ou modificação"38.

A evidência não é sentimento subjectivo ${ }^{39}$, mas a qualidade pela qual o sujeito supera a particularidade do seu acto para se vincular ao inteligível. Evidência é a luminosidade própria da ideia e não um estado psicológico: a verdade inteligível da ideia enquanto esta se impõe ao sujeito. No plano fenomenológico, a evidência significa

nos Entretiens: "Como os homens consideram como nada as ideias que têm das coisas, dão ao mundo criado muito mais realidade do que ele tem. (...) Pois, mais um passo (encore un coup), é muito mais fácil demonstrar a realidade das ideias ou, para utilizar os vossos termos, esse outro mundo cheio de belezas inteligíveis, do que demonstrar a existência deste mundo material". (Entretiens..., (Oeuvres Complètes, tomos XII-XIII, p. 36).

33 Méditations Chrétiennes et métaphysiques, I, 22, (Oeuvres Complètes, tomo X, p. 17).

A mesma tese é defendida em resposta a Arnauld: "É evidente que toda a modalidade de um ser particular não pode ser geral. Ora, eu penso num círculo em geral: a realidade objectiva do meu pensamento, ou a ideia desse círculo, não pode ser uma modalidade particular do meu espírito". (Recueil de toutes les réponses à Monsieur Arnauld, (Oeuvres Complètes, tomos VI-VII, p. 60).

34 "Porque não se deve imaginar que uma mesma ideia toque sempre a alma de uma mesma maneira. Pode afectá-la com uma infinidade de percepções todas diferentes; o que mostra bem que as ideias são muito diferentes das percepções que delas se tem". (Traité de l'amour de Dieu, (Oeuvres Complètes, tomo XIV, p. 12).

35 Entretiens..., I, x, (Oeuvres Complètes, tomos XII-XIII, p. 45).

36 Acerca deste tópico, veja-se Henry, Michel, "Le commencement cartésien et l'idée de la phénoménologie", in Depré, O. e Lories, D., Lire Descartes aujourd 'hui, Louvain-Paris, Ed. Peeters, 1997, pp. 208-209; Henry, Michel, Encarnação. Uma Filosofia da Carne, Lisboa, Círculo de Leitores, 2001, pp. 84-90.

37 "Não confundas nunca a evidência, que resulta da comparação entre as ideias, com a vivacidade dos sentimentos que te afectam e impressionam". (Entretiens..., (Oeuvres Complètes, tomos XII-XIII, p. 68).

38 Réflexions sur la prémotion physique, (Oeuvres Complètes, tomo XVI, p. 28).

39 "Os nossos sentimentos são confusos. São apenas modalidades da nossa alma que não podem iluminar-nos. Mas as ideias que a razão nos revela são luminosas: a evidência acompanha-as". (Entretiens..., Oeuvres Complètes, tomos XII-XIII, p. 86). 
fazer a experiência da passividade originária do espirito na sua relação com a verdade. Por conseguinte, a disciplina implicada na evidência comporta uma atitude de grande exigência intelectual de modo a eliminar não só os preconceitos dos sentidos e da opinião mas também a particularidade inerente ao meu pensar ${ }^{40}$. A cogitatio (o pensar) do espírito humano não se identifica com a Razão universal. Sob este aspecto, Malebranche foi o único "cartesiano" que seguiu a indicação de Descartes, expressa em carta a Arnauld (1648), segundo a qual a cogitatio é particular ${ }^{41}$. Em termos muito explícitos, o Tratado de moral parte justamente da assimetria entre espírito e razão: "Se o meu próprio espírito fosse a minha Razão, ou a minha luz, o meu espírito seria a razão de todas as inteligências. Com efeito, estou seguro de que a minha Razão ou a luz que me ilumina é comum a todas as inteligências. Ninguém pode sentir a minha própria dor: todo o homem pode ver a Verdade que eu contemplo. Portanto, isso significa que a minha dor é uma modificação da minha própria substância e que a Verdade é um bem comum a todos os espíritos" ${ }^{\prime 42}$.

3. A negação malebranchiana da capacidade representativa da consciência está de algum modo na contra-corrente da tendência mais genuína de finais do século XVII e que visa marcar a eficácia do exercício pensante na produção do conhecimento. Daí o vigor da reacção de Arnauld, cujo libelo Des vraies et des fausses idées é o manifesto da representação, elevada a paradigma da racionalidade.

A consciência intencional, na qual se irá rever a posteridade filosófica, é o reverso da consciência malebrancheanamente entendida como afecção do espírito pelas suas ocorrências internas: não a consciência de alguma coisa, mas simples consciência, sem correlato objectal, "sensiência", na expressão feliz de Sofia Miguens ${ }^{43}$. Ao invés, a consciência que representa as coisas exteriores e se representa a si mesma é uma consciência intelectual, um pensamento que acompanha virtualmente todos os outros pensamentos do espírito. O que está em confronto são duas figuras irredutíveis da consciência: uma consciência afectada, visceralmente inapta para conhecer, e uma consciência representativa, investida do poder de elucidação do mundo objectivo, ao qual está naturalmente ajustada. A interpretação heideggeriana do eu penso como eu

40 A disciplina exigida pelo Mestre interior nas Meditações é muito explícita a este respeito: "É preciso, meu Filho, que estejas extremamente atento às minhas respostas para as conceberes distintamente, é preciso que me escutes com muita humildade e respeito, a fim de que aquilo que te vou dizer te seja proveitoso. Com efeito, se os teus sentidos e as tuas paixões se não calarem, se os teus preconceitos se imiscuirem nas minhas respostas, e caso o espírito de orgulho ou a tua preguiça e a tua negligência te façam julgar a respeito daquilo que não concebes claramente, cairás em erros tanto mais perigosos quanto as verdades que quero ensinar-te são mais relevantes. Por conseguinte, sê humilde, atento, respeitador, desconfia de ti mesmo e põe a tua confiança em mim. Principalmente, rende-te apenas à evidência, que é o carácter da verdade: é o efeito da luz: é uma marca certa de que sou eu que falo". (Méditations Chrétiennes et Métaphysiques, XI, 5, (Oeuvres Complètes, tomo X, p. 117).

41 "Portanto, pelo pensamento não entendo algo de universal que compreenda todos os modos de pensar, mas uma natureza particular; que recebe todos aqueles modos" [it. meus] (Carta a Arnauld de 29.07. 1648).

42 Traité de Morale, I, I, ii, (Oeuvres Complètes, tomo XI, p. 18).

43 "O facto de a dor ter a vantagem (teórica...) de não representar nada, de ser um raw feeling, um sentimento cru - por oposição à aboutness ou intencionalidade que é o traço usualmente central na consideração da mente - faz com que ela abra a porta à teoria da interioridade como sensiência (sentience). Os problemas da sensiência são diferentes dos problemas da intencionalidade. Os últimos dizem directamente respeito à mente como representação de um exterior, enquanto os primeiros envolvem um sentimento de si daquele que respresenta, e por isso estão ligados ao teor da interioridade". (Miguens, Sofia, "Qualia e Razões. Uma teoria da interioridade natural", in VV AA, Dor e Sofrimento. Uma perspectiva interdisciplinar, Porto, Campo das Letras, 2001, p. 236). 
represento-me, pondo-me a mim próprio como objecto em face de mim como sujeito ${ }^{44}$, é muito problemática em face do texto cartesiano, do seu léxico e respectivo quadro sistemático, mas tem aqui um ponto de apoio insofismável.

Malebranche, apesar de assumir o rigor do método cartesiano e algumas teses nucleares do cartesianismo, v. g. o duàlismo, subverte doutrinas emblemáticas do sistema cartesiano, v. g. a da evidência do cogito e a da criação das verdades eternas. O resultado é uma filosofia original, que acentua dificuldades sentidas pelo próprio Descartes, introduz novas distinções e articulações, aumentando significativamente o nível de complexidade. Ao invés, Arnauld assume dogmaticamente as doutrinas tipicamente cartesianas e opera a simplificação máxima do sistema, não sendo, pois, de estranhar que a vulgata cartesiana se ajuste admiravelmente às teses do Teólogo jansenista.

Opondo-se ao realismo malebrancheano das ideias, Arnauld reconduz a ideia à esfera da imanência do sujeito: uma ideia verdadeira é o correlato noemático da concepção do espírito pensante. A ideia falsa é aquela que é hipostasiada como uma entidade sui generis à qual cabe a função de estabelecer a ligação entre o sujeito pensante e os objectos por ele visados. A percepção é também ideia, tem um conteúdo nocional próprio: "Disse que tomava pela mesma coisa a percepção e a ideia. Importa contudo notar que essa mesma coisa, se bem que única, tem duas relações: uma que a alma, que ela modifica, a outra com a coisa percebida, enquanto ela está objectivamente na alma; e que a palavra percepção marca mais directamente a primeira relação, e a ideia a segunda. Assim, a percepção de um quadrado marca mais directamente a minha alma como percebendo um quadrado, e $a$ ideia de um quadrado marca mais directamente o quadrado enquanto ele está objectivamente no meu espírito"45.

Pensar, perceber e representar são uma e a mesma coisa. O acto pensante, expresso pelo termo percepção, é essencial e formalmente representativo. A representatividade é a própria eficácia do espírito, não fazendo sentido recorrer a uma instância superior de validação: "Quando se diz que as nossas ideias e as nossas percepções (pois tomo isso pela mesma coisa) nos representam as coisas que concebemos e são imagens delas, é num sentido inteiramente diferente de quando se diz que os quadros representam os seus originais e são imagens deles, ou que as palavras proferidas ou escritas são as imagens dos nossos pensamentos. Porque, no que se refere às ideias, isso quer dizer que as coisas que concebemos estão objectivamente no nosso espírito e no nosso pensamento. Ora, essa maneira de estar objectivamente no espirito é tão particular ao espírito e ao pensamento, como sendo aquilo que constitui particularmente a sua natureza, que em vão se procuraria algo de semelhante em tudo o que não é espírito e pensamento"46.

O dualismo alma/corpo não tem nada de misterioso ou abissal, significa apenas o ajustamento e a proporção mútua entre o sujeito cognoscente e o objecto conhecido, anulando a distinção entre objecto percebido e objecto visado: "Ora, tendo Deus querido que o nosso espírito conhecesse os corpos e que os corpos fossem conhecidos pelo nosso espírito, foi sem dúvida mais simples tornar o nosso espírito apto a conhecer imediatamente os corpos, isto é, sem seres representativos, distintos das percepções (efectivamente, é neste sentido que tomarei sempre aqui a palavra imediatamente) e os corpos aptos a serem imediatamente conhecidos pelo nosso espírito, do que deixar a alma na impotência de os ver de outro modo que não mediante certos seres representativos, e de uma maneira tão desajeitada que nenhum homem sincero pode dizer de boa fé que a compreendeu"47.

44 Heidegger, M., Nietzsche II, Paris, Gallimard, 1971, pp. 114-128.

45 Arnauld, A., Des vraies et des fausses idées, Paris, Fayard, 1986, p. 44. Doravante, esta obra será referida pela sigla VFI.

46 VFI, p. 45.

47 VFI, p. 80. 
O sujeito vê-se, pois, investido do poder de fundação, é em si mesmo que apreende a inteligibilidade das coisas. O meu acto de pensar é representativo porque eu contenho em mim, sob o modo intencional, as coisas, reduzidas à condição de objectos. A objectividade é a marca da realidade enquanto apta a ser apreendida pelo sujeito que pensa de uma maneira clara e distinta. A inteligibilidade identifica-se com a "realidade objectiva da coisa", que se dá na "presença objectiva" ao sujeito: "Ora, juntando tudo isso ao que dissemos nas definições 3, 6 e 7, segue-se que, sendo toda a percepção essencialmente representativa de alguma coisa, e chamando-se em vista disso ideia, ela não pode ser essencialmente reflexiva sobre si mesma (essentiellement reflechissante sur elle même) sem que o seu objecto imediato seja essa ideia, isto é, a realidade objectiva da coisa que o meu espírito é dito perceber: de maneira que, se eu pensar no sol, a realidade objectiva do sol, que está presente ao meu espírito, é o objecto imediato dessa percepção" ${ }^{\prime 48}$.

Dado o carácter intencional do pensamento, que é sempre pensamento de alguma coisa ${ }^{49}$, também a consciência é interpretada segundo o modelo do pensar objectivante: o sujeito apreende-se tomando-se a si mesmo como objecto. A consciência significa a transparência do pensar a si mesmo, a plena identidade entre o pensante e o pensado. A percepção de si realiza-se pela ideia clara e distinta do pensamento substancial, denominado espírito ou alma. A consciência é uma representação do eu como unidade: uma representação ou ideia virtualmente presente em nós e que acompanha todos os nossos pensamentos ${ }^{50}$. O eu pensante é um verdadeiro suposto metafísico.

Arnauld distingue consciência implícita ou virtual e consciência explícita ou actual. Ao pensarmos, sentirmos, querermos, muitas vezes não reflectimos sobre o nosso acto, mas podemos sempre fazê-lo de uma maneira distinta. Nenhuma zona de penumbra afecta a luminosidade do eu, expressa na consciência. O estado pré-reflexivo é um nível elementar da consciência, que é sempre passível de apreensão intelectual. Todos os fenómenos interiores da consciência e do sentimento podem ser objecto de intelecção clara: "Ora, mesmo que se quisesse duvidar se a percepção que temos do nosso pensamento, quando o conhecemos (como) por si próprio sem reflexão expressa, é propriamente uma ideia, não se pode negar pelo menos que não tenhamos a facilidade de a conhecer mediante uma ideia; já que para isso se não exige mais do que uma reflexão expressa sobre o nosso pensamento. Porque então esse segundo pensamento que tem por objecto o primeiro será uma percepção formal deste e, por conseguinte, uma ideia. Ora, tal ideia será clara, uma vez que nos fará aperceber muito evidentemente aquilo de que é ideia. E, por conseguinte, é indubitável que vemos mediante ideias claras aquilo que vemos por sentimento e por consciência" [it. meu].

4. Arnauld mantém-se fiel ao intento cartesiano de uma mathesis homogénea, rejeitando a dualidade entre ciência e consciência: o cogito reassume o estatuto de paradigma do saber. Mais sensivel aos problemas deixados em aberto, Malebranche irá aprofundar o iniervalo imenso que Descartes reconhece existir entre a física e a moral, a ciência mais elevada, à qual cabe a tarefa de perscrutar o íntimo do homem: a meditação

48 VFI, pp. 52-53.

49 "Como, portanto, é claro que eu penso, é igualmente claro que penso em alguma coisa, isto é, que conheço e percebo alguma coisa. Porque o pensamento é essencialmente isso. E assim, não podendo haver pensamento ou conhecimento sem objecto conhecido, também não posso perguntar a mim mesmo a razão por que penso em alguma coisa, que não simplesmente porque penso, sendo impossível pensar sem que se pense em alguma coisa". (VFI, p. 22).

50 "Talvez haja em mim algum pensamento que não muda e que se poderia tomar pela essência da minha alma. (...) Encontro dois que se poderiam considerar como tais: o pensamento do ser universal e aquele que a alma tem de si mesma; efectivamente, parece que um e outro se encontram em todos os outros pensamentos. O do ser universal; porque todos os pensamentos encerram a ideia de ser, não conhecendo a nossa alma nada a não ser sob a noção de ser possivel ou existente. E o pensamento que a nossa alma tem de si mesma, porque, seja o que for que eu conheça, conheço que o conheço, por uma certa reflexão virtual que acompanha todos os meus pensamentos". (VFI, p. 23). 
e o exame de si são assumidos como via de aperfeiçoamento da pessoa moral ${ }^{51}$. Ao invés de Arnauld, que rejeita pura e simplesmente a legitimidade de uma moral filosófica ${ }^{52}$ e se opõe à tendência para erigir a consciência em instância de validação moral, Malebranche propõe-se elaborar uma moral que estabeleça a ponte entre filosofia e teologia ${ }^{53}$, na qual a universalidade do juízo ${ }^{54}$ se combina com a dimensão interior da vivência pessoal. A lei moral única, comum a Deus e aos espíritos criados, é o amor da Ordem ${ }^{55}$, isto é, o amor de cada ser na proporção da perfeição que ele encerra, do seu justo valor ${ }^{56}$.

A Ordem é a noção axial da moral. Sobrepondo-se à inteligibilidade geométrica, que considera as relações de grandeza entre os seres, exercendo-se sobre realidades homogéneas, a Ordem considera as relações de perfeição entre diferentes tipos de seres: "As relações de grandeza são entre as ideias dos seres da mesma natureza, por exemplo entre a ideia de uma toesa e a ideia de um pé; e as ideias dos números medem ou exprimem exactamente essas relações, se elas não forem incomensuráveis. As relações de perfeição são entre as ideias ou maneiras de ser de natureza distinta, por exemplo entre o corpo e o espírito, entre o redondo e o prazer. Mas tu não podes medir exactamente estas relações. Basta que compreendas que o espírito, por exemplo, é mais perfeito ou mais nobre do que o corpo, sem saber exactamente quanto" 57 . As primeiras são abstractas, as segundas regulam a acção ${ }^{58}$, sendo também chamadas "verdades práticas"

51 "Estuda o homem, a sua doença, as suas fraquezas, as suas inclinações, as leis da união entre a alma e o corpo, os sentidos, a imaginação, as paixões. Tal estudo é-te necessário para te conduzires; e, se reflectires bem sobre o que se passa em ti, tornar-te-ás rapidamente sábio acerca desta matéria". (Meditations..., XX, 20, Oeuvres, tomo X, p. 236).

52 A este respeito, veja-se Cardoso, A., "Uma nova heresia à medida de um novo mundo: a ofensiva de Arnauld contra a doutrina do pecado filosófico", Philosophica 15 (2000), pp. 117-133.

53 Em resposta à crítica de Arnauld ao seu Tratado da Natureza e da Graça, escreve Malebranche: "Arnauld põe-me a desempenhar dois personagens separados, o de Filósofo e o de Teólogo. Mas eu sou feito como os outros. Todos os teólogos são ao mesmo tempo Filósofos, tal como eu" (Recueil de toutes les réponses à Monsieur Arnauld, Oeuvres Complètes, tomo VIII-IX, p. 631$)$.

54 “Com efeito, julgar as coisas ao acaso, bem como por paixão ou por interesse, é julgar mal já que não é julgar por evidência e por luz. É julgar por si mesmo e não pela Razão, ou segundo as leis da Razão universal, Razão que, segundo digo, é a única superior aos espíritos e a única que tem o direito de se pronunciar sobre os juízos que eles formam". (Traité de Morale, I, I, VIII), (Oeuvres Complètes, tomo XI, p. 20).

55 "Como a maioria dos homens não sabem distintamente que só a Sabedoria Eterna é que os ilumina e que as ideias inteligíveis que constituem o objecto imediato do seu espírito não foram criadas, imaginam que as leis eternas e as verdades imutáveis são estabelecidas como tais pela vontade livre de Deus. E foi isso que levou Descartes a dizer que Deus poderia ter feito com que 2 vezes quatro não fossem 8 e que os três ângulos de um triângulo não fossem iguais a dois rectos, porque, diz ele, não há ordem nem razão de bondade e de verdade que não dependa de Deus e porque foi ele que, desde toda a eternidade, ordenou e estabeleceu como soberano Legislador as verdades eternas. Este homem sábio não atentava em que há uma ordem, uma lei, uma razão soberana que Deus ama necessariamente, que lhe é coeterna e segundo a qual é necessário que ele aja, suposto que queira agir". (Recherche de la vérité, Eclaricissement VIII, (Oeuvres Complètes, tomo III, pp. 85-86).

56 "Porque a ordem, considerada especulativa e precisamente enquanto ela encerra as relações de perfeição, ilumina o espírito sem o impressionar; e a ordem, considerada como a lei de Deus, como a lei de todos os espíritos, considerada precisamente enquanto tem força de lei, pois Deus ama e quer invencivelmente que se ame a Ordem, ou todas as coisas na proporção em que são amáveis: a ordem, digo, como princípio e regra natural e necessária de todos os movimentos da alma, toca, penetra, convence o espírito sem o esclarecer". (Traité de Morale, (Oeuvres Complètes, tomo XI, p. 68).

57 Meditations..., IV, 7, (Oeuvres Complètes, tomo X, p. 38).

58 Op. cit., p. 39.

59 Traité de Morale, I, I, XIX, (Oeuvres Complètes, tomo XI, p. 24). 
A Ordem é mais do que a simples Verdade: acrescenta-lhe a dimensão do valor. Quando pergunto pelo valor do meu próprio eu, o que está em causa é algo mais do que os atributos que qualificam o meu ser.

O excesso de sentido que a Ordem transporta consigo é acompanhada por uma diminuição de inteligibilidade. Com efeito, a ordem escapa à evidência geométrico-metafísica, em virtude do seu modo próprio de doação, a saber, a percepção da beleza. Daí a advertência do Mestre interior: "Deves contemplar mais a beleza da ordem do que a evidência da verdade" ${ }^{30}$. No plano da experiência vivida, o aperfeiçoamento moral é acompanhado pela intensificação do sentido estético.

Percepção da beleza e prazer formam um só: o prazer não é um efeito dessa percepção, mas identifica-se plenamente com ela: “... pois todo o sentimento agradável ou desagradável mais não é do que a percepção de uma ideia que afecta a alma de diversas maneiras" ${ }^{\prime \prime 1}$. A moral institui, assim, um modo de inteligibilidade mais complexo do que o da mathesis científica, articulando a luminosidade da razão com a obscuridade do sentimento: "O conhecimento da ordem que é a nossa lei indispensável é uma amálgama de ideias claras e sentimentos obscuros"

A relação com a Ordem é intelectual, mas é também afectiva, já que ela "está gravada no coração do homem" "63. Daí a diferença entre a moralidade aparente daquele que se submete à voz da razão e lhe obedece cegamente, por um lado, e a moralidade verdadeira, expressa no amor da Ordem. No léxico do autor, o cumprimento do dever não se identifica com a virtude: "Um dos maiores defeitos que se notam nos livros de certos Filósofos é que eles confundem os deveres com as virtudes, ou que dão o nome de virtudes aos simples deveres. (...) Logo, a disposição para observar um tal desses deveres não é propriamente a virtude, sem o amor da Ordem"64. Significa isto que não há um índice objectivo do bem, que a simples observação exterior das acções humanas não é suficiente para estabelecer a sua qualidade moral. Consideradas em si mesmas, a um olhar pretensamente objectivo, as acções são o que há de mais equivoco e confuso ${ }^{65}$. Por conseguinte, a consideração dos "nossos sentimentos e movimentos interiores" "é de uma consequência infinita para a Moral" ${ }^{66}$. A virtude é amor, ou seja, o acto da vontade. Ora, a vontade só se determina a amar aquilo que lhe dá prazer: "De modo que, se considerarmos o prazer em geral, enquanto ele contém os prazeres racionais bem como os sensíveis, parece-me certo que é ele o princípio ou o motivo único do amor natural ou de todos os movimentos da alma para qualquer bem, já que só se pode amar o que agrada"67.

A moral inclui dois planos, que "importa não confundir" ${ }^{68}$, o do fim visado pela acção e o do motivo subjectivo que determina a vontade a amar tal objecto em vez de outro. A questão reside no modo de articulação entre estes dois planos, mais precisamente, na ordenação mútua entre vontade e afecto: $o$ afecto é o estrato fundador da vontade. Malebranche demarca-se da concepção fantasiosa da vontade entendida como liberdade de equilibrio, que se determina indiferentemente por um ou outro motivo ${ }^{69}$.

${ }_{61}$ Méditations..., III, 23, (Oeuvres Complètes, tomo X, p. 34).

61 Traité de l'amour de Dieu, (Oeuvres Complètes, tomo XIV, p. 12).

62 Traité de Morale, I, V, § xix, (Oeuvres Complètes, tomo XI, p. 67).

63 Traité de Morale, I, II, §ix, (Oeuvres Complètes, tomo XI, p. 33).

64 Traité de Morale, I, II, IV-V, (Oeuvres Complètes, tomo XI, pp. 30-31).

65 «Se quiséssemos guiar-nos pelos exemplos e julgar as coisas pela opinião, enganar-nos-íamos permanentemente. Porquanto não há nada mais equívoco e mais confuso do que as acções dos homens e muitas vezes não há nada mais falso do que aquilo que passa por certo em povos inteiros". (Traité de Morale, I, V, xvi, (Oeuvres Complètes, tomo XI, p. 66).

${ }_{66}$ Ibid., p. 67.

67 Recherche de la vérité, (Oeuvres Complètes, tomo II, p. 47).

68 Traité de l'amour de Dieu, (Oeuvres Complètes, tomo XIV, p. 10).

69 Traité de l'amour de Dieu, (Oeuvres Complètes, tomo XIV, p. 19 e 27). 
O Oratoriano introduz a inclinação na constituição íntima da vontade, definida como impressão originária para o bem em geral: “(...) é essa impressão contínua de Deus que faz a vontade dos homens, já que eles não são capazes de amar nenhum bem em particular senão mediante o amor natural e invencível que Deus lhes dá para o bem em geral" $" 70$.

A vontade determina-se livremente, mas ela tem uma função integradora relativamente aos sentimentos naturais: incumbe-lhe elevar o sentimento a uma dimensão superior, não anulá-lo. O exercício da vontade pressupõe uma natureza humana que age por motivação, de um modo espontâneo. Os sentimentos formam-se em nós, sem nós ${ }^{71}$. A passagem da espontaneidade natural à liberdade moral significa o salto do sentir ao consentir: "Quando digo que temos sentimento interior da nossa liberdade, não pretendo defender que tenhamos sentimento interior de um poder de nos determinar a querer qualquer coisa sem nenhum motivo físico, poder que algumas pessoas chamam indiferença pura. Tal poder parece-me encerrar uma contradição óbvia. Trata-se de algo bastante óbvio, se se interpretou bem o que acabo de dizer; com efeito, é claro que é preciso um motivo, que é preciso por assim dizer sentir antes de consentir"72.

A perfeição moral, expressa no amor prevalecente da Ordem, acima de todas as coisas, joga com o amor de si, que é o motivo natural da acção humana em geral. Trata-se de um motivo natural, que se situa aquém do bem e do mal, numa esfera de a-moralidade: "Assim, o amor-próprio, o desejo de ser feliz não é virtude nem vício, mas é o motivo natural da virtude, e que nos pecadores se torna motivo do vício"73. Ao invés da apatheia estóica ${ }^{74}$, a virtude cristã tal como Malebranche a entende apura e intensifica a capacidade emocional do homem. O uso das paixões é o aspecto fundamental da moral: querer significa "consentir num motivo"75.

A vontade livre está na continuidade da espontaneidade natural. O ideal de união perfeita com Deus mediante um amor livre esclarecido não dispensa, antes exige, o conhecimento do modo como se formam e desenvolvem em nós as inclinações que qualificam e conferem uma identidade própria ao espírito de cada um de nós. A razão indica o fim a alcançar, a ciência do homem revela a intimidade de cada um, a relação de si consigo, que é a pedra de toque da moralidade.

Nas palavras do autor, a ciência do homem é meramente experimental: “O conhecimento do homem é de todas as ciências a mais necessária ao nosso tema [a moral]. Mas não é mais do que uma ciência experimental, que resulta da reflexão sobre o que se passa em si mesmo"76. A base desta ciência é a reflexão sobre os seus próprios fenómenos ou, como é dito algumas linhas acima, "sobre os nossos sentimentos e movimentos interiores a fim de descobrir o seu encadeamento e relações, e as causas naturais ou ocasionais que os excitam". Trata-se de uma ciência experimental, que incide sobre factos incontestáveis, mas que carecem da luminosidade dos princípios evidentes em que assenta a inteligibilidade físico-geométrica. Fenomenologia é outro

Meditations..., XV, 10, (Oeuvres Complètes, tomo X, p. 168).

Utilizando o termo paixão no sentido amplo que lhe é atribuído na literatura filosófica do século XVII, escreve Malebranche: "Todas estas coisas que acabamos de explicar a respeito das paixões em geral não são livres: estão em nós sem nós e só o consentimento da nossa vontade é que depende absolutamente de nós". (Recherche de la vérité, (Oeuvres Complètes, tomo II, p. 158).

72 Recherche de la vérité, (Oeuvres Complètes, tomo III, p. 29).

73 Traité de Morale, II, XIV, iv, (Oeuvres Complètes, tomo XI, p. 270).

74 Sob este aspecto, Malebranche insere-se na corrente de espiritualidade cristã que, ao longo do século XVII, se opõe aos Estóicos, valorizando a dimensão do sentimento (Recherche de la vérité, Oeuvres Complètes, tomo XI, pp. 76-77).

75 Réflexions sur la prémotion physique, (Oeuvres Complètes, tomo XVI, p. 50).

76 Traité de Morale, I, V, xvii, (Oeuvres Complètes, tomo XI, p. 67). 
modo de dizer esta ciência da consciência como modo original de o espírito fazer a experiência de si.

A consciência é pontual, o seu campo próprio restringe-se à experiência actual, àquilo que efectivamente ocorre em nós. Ora, o dado imediato que se apresenta à consciência remete para um fundo apetencial pelo qual se efectua a continuidade do eu. Esse fundo apetencial é constituído por disposições internas que formam a estrutura dinâmica do nosso nós mesmos ${ }^{77}$. Na medida em que ela visa perscrutar a motivação profunda dos nossos actos, a ciência do homem resiste à ilusão da autonomia da consciência, radicando-a na vida de um eu, que é uma ipseidade em construção, não um ser fixo e naturalmente dado.

77 "Além disso, como a vontade não é nunca obrigada à força, nós imaginamos que tudo o que queremos, o queremos precisamente porque o queremos. De modo nenhum pensamos que as nossas vontades se excitam em nós em consequência das nossas disposições interiores. Porque, sendo de facto essas disposições modificações do nosso ser próprio que nos são desconhecidas, elas fazem-nos querer de uma maneira que parece que isso depende de nós: pois nós queremos tão agradavelmente que cremos que nada nos obriga a querer. É verdade que então nada nos obriga a querer senão nós mesmos. Mas o nosso nós mesmos (nôtre nous-mêmes) não é o nosso ser puramente natural ou perfeitamente livre para o bem e para o mal: é o nosso ser disposto a um ou outro através de modificações que o corrompem ou aperfeiçoam e que nos tornam justos ou pecadores aos olhos de Deus. E são essas disposições, que é preciso aumentar ou destruir mediante os actos, que são as causas naturais dos hábitos". (Traité de Morale, I, IV, § iii, (Oeuvres Complètes, tomo XI, p. 52). 
